\title{
Correction to: A New Approach for Dry Eye Management by Mucoadhesive In situ Gel of Vitamin B12: Formulation, In vitro and In vivo Assessment
}

\author{
Soad A. Mohamad, ${ }^{1}$ Eman Alaaeldin, ${ }^{1,2}$ Raafat M. A. Abdallah, ${ }^{3}$ and Heba F. Mansour ${ }^{2,4}$
}

Published online 6 April 2021

Correction to: AAPS PharmSciTech volume 22, Article number: 87 (2021). https://doi.org/10.1208/s12249-021-01957-4

During the production process, the cited reference numbers throughout the manuscript were inadvertently shifted. The original article has been corrected.

Publisher's Note Springer Nature remains neutral with regard to jurisdictional claims in published maps and institutional affiliations.

The online version of the original article can be found at https:// doi.org/10.1208/s12249-021-01957-4

\footnotetext{
${ }^{1}$ Department of Pharmaceutics, Faculty of Pharmacy, Deraya University, Minia, Egypt.

${ }^{2}$ Department of Pharmaceutics, Faculty of Pharmacy, Minia University, P.O. Box: 61111, Minia, Egypt.

${ }^{3}$ Department of Ophthalmology, Faculty of Medicine, Minia University, Minia, Egypt.

${ }^{4}$ To whom correspondence should be addressed. (e-mail: heba_mansour@mu.edu.eg)
} 